\title{
A cross-sectional study of the nutritional quality of student canteen purchases from New South Wales primary-school canteens
}

\author{
Tessa Delaney ${ }^{1,2,3,4, *}$, Rachel Sutherland ${ }^{1,2,3,4}$, Rebecca Wyse ${ }^{1,2,3,4}$, \\ Luke Wolfenden 1,2,3,4, Christophe Lecathelinais ${ }^{1,2,3,4}$, Lisa Janssen², Kathryn Reilly 1,2,3,4, \\ John Wiggers ${ }^{1,2,3,4}$ and Sze Lin Yoong ${ }^{1,2,3,4}$ \\ 'School of Medicine and Public Health, University of Newcastle, Booth Building, Wallsend Campus, University Drive, \\ Callaghan, NSW 2308, Australia: ${ }^{2}$ Hunter New England Population Health, Wallsend, NSW, Australia: ${ }^{3}$ Hunter \\ Medical Research Institute, New Lambton Heights, NSW, Australia: ${ }^{4}$ Priority Research Centre for Heath Behaviour, \\ University of Newcastle, Callaghan, NSW, Australia
}

Submitted 24 September 2018: Final revision received 18 March 2019: Accepted 23 April 2019; First published online 25 July 2019

\begin{abstract}
Objective: To assess the nutritional quality of student canteen purchases at recess and lunch, including: (i) the mean energy (kilojoules), saturated fat (grams), total sugar (grams) and $\mathrm{Na}$ (milligrams) and percentage of energy from saturated fat and total sugar; and (ii) the proportion and types of foods purchased that are healthier (green) and less healthy (amber/red) according to a state school canteen policy. Design: A cross-sectional study of student canteen food and beverage recess and lunch purchases.

Setting: Twenty-six randomly selected government primary schools that were noncompliant with a state school canteen policy from a region of New South Wales, Australia, were approached to participate.

Participants: Students (aged 5-12 years) of participating schools.

Results: Eighteen schools (69\%) consented to participate. On average students' recess purchases contained $571.2 \mathrm{~kJ}$ energy, $1.6 \mathrm{~g}$ saturated fat, $11.6 \mathrm{~g}$ total sugar and $132.4 \mathrm{mg} \mathrm{Na}$ with $10.0 \%$ of energy from saturated fat and $37.8 \%$ of energy from total sugar. Students' lunch purchases contained $685.4 \mathrm{~kJ}$ energy, $1.8 \mathrm{~g}$ saturated fat, $12.7 \mathrm{~g}$ total sugar and $151.4 \mathrm{mg} \mathrm{Na}$ with $9.5 \%$ of energy from saturated fat and $31.8 \%$ of energy from total sugar. Less healthy items represented 72 and $76 \%$ of all items purchased at recess and lunch, respectively, with 'savoury snacks' and 'sugar-sweetened ice blocks and slushies' being the most common recess and lunch purchases, respectively.

Conclusions: There is considerable scope to improve the nutritional quality of student purchases from primary-school canteens, with a high percentage of energy from total sugar. Future research is required to identify effective strategies to enhance compliance with canteen policies and support the purchase of healthier foods from school canteens.
\end{abstract}

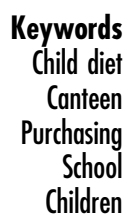

Poor diet, including the overconsumption of foods high in energy, saturated fat, salt and sugar, is one of the leading causes of non-communicable disease internationally ${ }^{(1)}$. Data from population samples of school-aged children in the $\mathrm{UK}^{(2)}$, the $\mathrm{USA}^{(3)}$ and Australia( ${ }^{(4)}$ indicate children overconsume 'energy-dense nutrient-poor' foods that are high in fat, salt and sugar, particularly those of lower socio-economic status ${ }^{(5)}$. Dietary behaviours established in childhood track into adulthood and predict future chronic disease ${ }^{(6)}$. As such improving child diet is a public health priority in Australia and internationally in order to reduce the burden from chronic diseases ${ }^{(1)}$.

Schools are recommended as a setting to improve child $\operatorname{diet}^{(7)}$ as they provide access to large numbers of children and are a setting where children can consume up to $40 \%$ of their daily requirements ${ }^{(8)}$. In Australia, as in other 
countries including New Zealand and Canada ${ }^{(9,10)}$, school canteens sell foods and beverages to students at meal breaks (recess and lunch) instead of, or in addition to, foods brought from home. They also represent a significant food provider for children ${ }^{(11)}$. For example, $95 \%$ of Australian students attend a school with a canteen, with $55 \%$ of students attending such schools purchasing lunch at least weekly, compared with just $23 \%$ of students purchasing from fastfood outlets each week ${ }^{(11)}$. In recognition of the importance of school canteens and similar school food services, the WHO recommends the implementation of school food and beverage policies as a strategy to improve the nutrition of children ${ }^{(1)}$.

Despite the potential contribution of foods purchased at the canteen to overall child dietary intake, in the past 10 years there has been little published research about the nutritional quality of student canteen purchases. A 2015 systematic review identified just five studies that examined the purchasing practices of school students at Australian school canteens ${ }^{(12)}$. All studies found that 'energy-dense nutrient-poor' foods were the most frequent type of food purchased from this setting ${ }^{(12)}$. The largest study in that review was a cross-sectional study conducted in 2004 of 2224 primary-aged students attending sixteen government primary schools in the state of New South Wales (NSW) ${ }^{(13)}$. The study found that the foods most frequently purchased from school canteens included pies and sausage rolls (consumed regularly by $54 \%$ ), pizza products (30\%), processed and crumbed chicken (29\%) and hot dogs $(18 \%)^{(13)}$. While such evidence suggests that the quality of foods purchased from canteens may be poor, all studies included in the review: were conducted prior to the implementation of relevant state and/or national canteen policy (with the majority ( $n$ 4) of included studies conducted prior to 2005); relied on self-report data; and described only the type of food purchased without considering other key nutrients associated with poor health outcomes, such as energy, sugar, saturated fat and $\mathrm{Na}^{(1)}$. To address these evidence limitations, the present study was undertaken to examine the nutritional quality of foods purchased by children from the school canteen and specifically to:

1. Assess the nutrient composition of student purchases including the mean (i) energy (kilojoules), (ii) saturated fat (grams), (iii) total sugar (grams) and (iv) $\mathrm{Na}$ (milligrams); and the percentage of energy coming from (v) saturated fat and (vi) total sugar of student recess and lunch purchases.

2. Describe the nutritional value of foods and beverages purchased by students at recess and lunch including the proportions and types of foods and beverages that are healthier and less healthy.

3. Examine the associations between school characteristics (school location, school socio-economic region) and nutrient composition (mean energy, saturated fat, total sugar and $\mathrm{Na}$, percentage of energy coming from saturated fat and total sugar) and nutritional value (healthier/less healthy) of student recess and lunch purchases.

\section{Method}

\section{Context}

In 2005, the NSW Government released the Fresh Tastes @ School: NSW Healthy School Canteen Strategy (FT@S) in response to the increasing levels of overweight and obesity in children ${ }^{(14)}$. FT@S classifies menu items (e.g. foods and beverages) as 'red' (low in nutritional quality), 'amber' (moderate nutritional quality) or 'green' (higher nutritional quality), based on their nutritional content (energy, saturated fat and $\mathrm{Na})^{(14)}$. The policy required NSW government school canteens to remove red items from regular sale, not let amber items dominate the menu and to fill the menu $(\geq 50 \%)$ with green items ${ }^{(15)}$.

\section{Design and setting}

A cross-sectional study was undertaken in the Hunter Region, a geographically and socio-economically diverse region in NSW, Australia. The Hunter Region encompasses major city, inner regional and outer regional areas ${ }^{(16)}$. Government schools are the leading provider of education in the Hunter Region, NSW and Australia ${ }^{(17)}$. Schools in the Hunter Region also have similar student enrolments and socio-economic characteristics to those in $\mathrm{NSW}^{(18)}$.

\section{Sample and recruitment}

Twenty-six government primary schools catering for students aged 5-12 years that (i) had an operational canteen, (ii) were non-compliant with FT@S and (iii) were in the control arm of a larger randomised controlled trial $(\mathrm{RCT})^{(19)}$ were included in the current study. The larger RCT included seventy randomly selected government primary schools from the Hunter Region. The RCT sought to test the effectiveness of a 12-14-month intervention to improve canteen compliance with FT@S (trial registry ACTRN12613000311752; ethics approval numbers: Hunter New England Human Research Ethics Committee, 06/07/26/4.04; NSW Department of Education and Communities, SERAP 2012277; University of Newcastle, $\mathrm{H}-2008-0343)$. Schools were eligible to participate in the larger RCT if they (i) had an operational canteen, (ii) were government schools and (iii) were non-compliant with FT@S. Approximately $90 \%$ of all government primary schools in the Hunter Region were non-compliant with FT@S and therefore eligible to participate in the larger $\mathrm{RCT}^{(19)}$. Schools were ineligible to participate in the larger RCT if they enrolled both primary and secondary students or catered exclusively for students with special needs. To recruit schools for the current study, a nested sample of fifty 
of the seventy schools were randomly approached (using a random number function in Excel, version Microsoft Office Professional Plus 2013) in 2015 to participate in canteen observations to assess student purchases. In order to estimate usual purchasing behaviour of students (i.e. in the absence of any intervention), only schools that were allocated to the control arm (twenty-six of the fifty approached) were included in the current study. Principals of the twentysix randomly selected schools received an information letter inviting their school to participate in the study and a follow-up telephone call to provide consent for a oneday observation to assess canteen purchases. All students who made a canteen purchase from consenting schools during the one-day observation were included in the study.

\section{Data collection and measures}

\section{Canteen purchases}

Student purchase data, including purchases that were preordered or made over the counter, were collected from participating school canteens during a one-day observation (on a day of the week nominated by the canteen manager) from 09.00 to 14.30 hours. Observations were conducted by dietitians using data collection tools and protocols designed specifically for the study and piloted in two canteens ${ }^{(20)}$. All dietitians were trained in data collection procedures during a $7 \mathrm{~h}$ workshop and were required to meet $100 \%$ accuracy in recording of students' purchases in a hypothetical canteen setting.

Depending on the size of the canteen and number of service lines, two or three dietitians audited student canteen purchases as they were made and recorded all items purchased by each student at each meal break ('recess' and 'lunch') using a standardised data collection checklist. Data checks were performed in $20 \%$ of schools where each individual student purchase was recorded by two independent dietitians. Inter-rater agreement between the dietitians in the products recorded per student purchase was on average $95 \%$ (level of disagreement range $=0-11 \cdot 1 \%$ ).

\section{Nutrient composition of student purchases}

To determine the nutrient profile (including energy, saturated fat, total sugar and $\mathrm{Na}$ content) of purchases, dietitians took an inventory of all items sold by the canteen. For packaged foods, dietitians recorded the product name, brand, serving size, and the energy (kJ), saturated fat $(\mathrm{g})$, total sugar (g) and $\mathrm{Na}(\mathrm{mg})$ per $100 \mathrm{~g}$ based on information provided on product labels. For unpackaged foods (e.g. freshly prepared foods), dietitians obtained recipe information including the recipe yield, ingredients list and serving size from the canteen manager. A dietitian then used a recipe conversion database, Foodworks ${ }^{\circledR}$ version 7 (Xyris Software, Highgate Hill, Australia), to determine the nutrient profile for each unpackaged item. The mean energy (kJ), saturated fat (g), total sugar (g) and $\mathrm{Na}(\mathrm{mg})$ for each purchase (consisting of one or more items) was calculated by combining the purchasing data with the nutrient profile of each item. The percentage of energy from saturated fat and total sugar for each purchase was determined based on internationally accepted conversion factors of 37 and $16.7 \mathrm{~kJ} / \mathrm{g}$, respectively ${ }^{(21)}$.

\section{Nutritional value (healthier or less healthy) and type of items purchased by students}

Following the one-day observation, all items on the menu were independently classified as 'red', 'amber' or 'green' according to the FT@S criteria by two dietitians and following procedures previously used by the research team ${ }^{(19,22)}$. Discrepancies in menu item classification were resolved through discussion and consensus between the two dietitians or, if agreement could not be reached, with a third dietitian. These classifications were used to determine the mean proportion of all items that were purchased and classified as 'healthier' ('green') and 'less healthy' ('amber'/'red') at recess and lunch. The approach of splitting the three classifications ('green', 'amber' and 'red') into two ('healthy' and 'less healthy') is consistent with other published canteen literature $^{(23)}$ and aligns with Australian ${ }^{(24)}$ and International Dietary Guidelines ${ }^{(25,26)}$. Additionally, as FT@S required canteens in NSW to restrict the sale of 'red' foods (to no more than twice per term) ${ }^{(14)}$, the decision was made to combine 'amber' and 'red' into a 'less healthy' category.

Dietitians also used the FT@S Canteen Menu Planning Guide $^{(14)}$ to describe the most common types of foods purchased by students (Table 1). The Canteen Menu Planning Guide $^{(14)}$ includes a comprehensive list of the types of foods and beverages (e.g. savoury pastries) that may appear on a canteen menu and their corresponding FT@S classification (red, amber or green). Each item purchased was assigned to its corresponding food group within this guide (e.g. 'potato crisps' were assigned to the 'savoury snack food' group) to describe the top ten foods or beverages purchased by students at each meal break.

\section{School and canteen characteristics}

School size and postcode were obtained from the Department of Education My School website ${ }^{(27)}$. NSW Department of Education School Directory classifications $^{(28)}$ were used to assign schools as small ( $<160$ students enrolled) and medium/large ( $\geq 160$ students). Median Socio-Economic Indexes For Australia (SEIFA) values were used to dichotomise schools into 'higher' and 'lower' socio-economic regions using the SEIFA database ${ }^{(29)}$. SEIFA ranks areas in Australia according to relative socio-economic advantage and disadvantage and is based on postcode ${ }^{(29)}$. School postcodes were also used to categorise schools into 'major cities' or 'inner regional' areas using the Accessibility/Remoteness Index of Australia (ARIA) ${ }^{(16)}$. Canteen manager employment status ('paid' or 'volunteer') was obtained from a telephone call with the school canteen manager as part of the larger $\mathrm{RCT}^{(19)}$. 
Table 1 Food and beverage classifications according to the criteria of the New South Wales government school-canteen policy Fresh Tastes @ School (FT@S) $)^{(14)}$

\begin{tabular}{|c|c|}
\hline Green & Amber and red \\
\hline $\begin{array}{l}\text { 'Healthier': contain less saturated fat and/or sugar and/or } \\
\text { salt; these foods help to avoid excess energy intake } \\
\text { - Breakfast cereals high in fibre, low in saturated fat and } \\
\text { added sugar } \\
\text { - Breads and alternatives with low levels of fat and sugar (e.g. } \\
\text { pikelets, homemade herb and garlic breads) } \\
\text { - Baked potato } \\
\text { - Pasta products (small servings, may contain lean meat, } \\
\text { vegetables, low-fat dairy) } \\
\text { - Pizza (homemade with lean meat, vegetables or low-fat } \\
\text { cheese) } \\
\text { - Rice and noodles lower in salt (e.g. sushi, plain rice) } \\
\text { - Salads } \\
\text { - Sandwiches, wraps and burgers with lean meats, egg or } \\
\text { salad ingredients } \\
\text { - Popcorn (unflavoured) } \\
\text { Frozen fruit juice, e.g. fruit juice ice blocks or slushies } \\
\text { (<200 ml) } \\
\text { - Fruit } \\
\text { - Vow-fat dairy foods } \\
\text { - Wegetables } \\
\text { - Low-fat milks (including flavoured) } \\
\text { - Fruit juice <200 ml }\end{array}$ & $\begin{array}{l}\text { 'Less healthy': contain higher levels of saturated fat and/or sugar and/or } \\
\text { - salt; these foods can contribute to excess energy intake } \\
\text { - Breakfast cereals high in saturated fat and added sugar } \\
\text { - Breads and alternatives with high levels of fat or sugar (e.g. finger buns, } \\
\text { - Ovets with jam, cheese and bacon rolls, commercial garlic breads) } \\
\text { - Pasta products (large servings, may contain processed meat, full-fat dairy) } \\
\text { - Pizza (commercial or homemade with processed meats) } \\
\text { - Rice and noodles higher in salt (e.g. hot noodle cups) } \\
\text { - Salads with crumbed meats } \\
\text { - Sandwiches, wraps or burgers with crumbed meats or spread } \\
\text { - Savoury pastries (e.g. pies, sausage rolls) } \\
\text { - Crumbed chicken, fish, meat or vegetable products } \\
\text { - Ice creams, milk-based ice confections and indulgent dairy desserts } \\
\text { - Spring rolls, chiko rolls and dim sims } \\
\text { - Sauces and gravy } \\
\text { - Cakes, muffins and sweet pastries } \\
\text { - Confectionery } \\
\text { - Full-fat dairy foods } \\
\text { - Snack food bars and sweet biscuits } \\
\text { - Savoury snack foods (e.g. crisps, flavoured popcorn) } \\
\text { - Ice blocks or slushies (sugar or artificially sweetened; >200 ml fruit juice) } \\
\text { - Sugar- and artificially sweetened drinks } \\
\text { - Full-fat milks }\end{array}$ \\
\hline
\end{tabular}

\section{Analysis}

Statistical analyses were performed using the statistical software package SAS version 9.3. Descriptive statistics were used to describe the characteristics of participating schools; the nutrient composition (i.e. energy, saturated fat, total sugar and $\mathrm{Na}$ content) of student purchases; the nutritional value (healthier/less healthy); and types of foods purchased by students at recess and lunch. As the nutrient data (energy, saturated fat, total sugar and $\mathrm{Na}$ ) were not normally distributed, the median and interquartile range were presented in place of the mean and standard deviation. The unit of analysis for nutrient composition was the 'purchase', which could consist of multiple items (e.g. one 'purchase' could consist of three food items). The unit of analysis for nutritional value (healthier/less healthy) was the individual food item. The results are reported separately for recess and lunch. We expected that locality was an important predictor of healthiness of student purchases, as such univariate analyses were undertaken to examine the association of school characteristics (e.g. socio-economic area and geographical location) with the nutrient composition and nutritional value of student recess and lunch purchases. Linear mixed-effect regression models were used to assess the association between nutrient composition (energy, saturated fat, $\mathrm{Na}$ and total sugar; percentage of energy from saturated fat and total sugar) and school characteristics (socio-economic area and geographical location) of student recess and lunch purchases. Logistic mixed-effect regressions were used to test the association between nutritional value (healthier/less healthy) and school characteristics of student recess and lunch purchases. All models included the school ID as a random effect to account for potential school level clustering. Statistical significance was set at $P<0.05$.

\section{Results}

Of the twenty-six control schools that were randomly selected to participate in the study, eighteen schools (69\%) consented and were included in the analyses. Among the eight non-consenting schools one did not consent in time and seven declined to participate, $75 \%$ were located in higher socio-economic areas, 62.5\% in major cities and $75 \%$ had $\geq 160$ student enrolments. The characteristics of participating schools and school canteens can be seen in Table 2. Of consenting schools, $67 \%$ were located in major cities, $78 \%$ had $\geq 160$ student enrolments and $61 \%$ of schools were located in regions of higher socioeconomic status (Table 2). There were no significant differences between consenting and non-consenting schools by socio-economic region, remoteness or school size. There were also no significant differences between the schools included in the study and government primary schools in the Hunter Region by socio-economic region, remoteness or school size ${ }^{(18)}$. A total of 2310 purchases were made by students across the eighteen schools with 1666 purchases made at lunch and 644 purchases made at recess. The mean number of items per purchase was 1.5 (SD 0.7) and 1.3 (SD 0.6) for lunch and recess, respectively. 
Table 2 Characteristics of participating schools and canteens, New South Wales, Australia, 2015

\begin{tabular}{|c|c|c|c|}
\hline \multirow[b]{2}{*}{ Characteristic } & & \multicolumn{2}{|c|}{$N 18$} \\
\hline & & $n$ & $\%$ \\
\hline \multirow[t]{2}{*}{ School size } & Medium/large ( $\geq 160$ students) & 14 & 78 \\
\hline & Small (<160 students) & 4 & 22 \\
\hline \multirow[t]{2}{*}{$\begin{array}{l}\text { Socio-economic } \\
\text { region* }^{*}\end{array}$} & $\begin{array}{l}\text { Higher (socio-economically } \\
\text { advantaged) }\end{array}$ & 11 & 61 \\
\hline & $\begin{array}{l}\text { Lower (socio-economically } \\
\text { disadvantaged) }\end{array}$ & 7 & 39 \\
\hline \multirow[t]{2}{*}{ ARIA† } & Major cities & 12 & 67 \\
\hline & Inner regional & 6 & 33 \\
\hline \multirow{2}{*}{$\begin{array}{l}\text { Type of canteen } \\
\text { manager }\end{array}$} & Paid & 14 & 78 \\
\hline & Volunteer & 4 & 22 \\
\hline
\end{tabular}

*Status was determined based on the postcode of the school locality and the Socio-Economic Indexes for Areas 2011.

TARIA was determined based on the postcode of the school locality and the Accessibility/Remoteness Index of Australia (ARIA).

\section{Nutrient composition (energy, saturated fat,} sodium and total sugar) of student purchases

As seen in Table 3, the nutrient composition of student purchases at recess was $571.2 \mathrm{~kJ}$ of energy, $1.6 \mathrm{~g}$ of saturated fat, $11.6 \mathrm{~g}$ of total sugar and $132.4 \mathrm{mg}$ of $\mathrm{Na}$ with $10.0 \%$ of energy from saturated fat and $37.8 \%$ of energy coming from total sugar. The nutrient composition of student purchases at lunch was $685.4 \mathrm{~kJ}$ of energy, $1.8 \mathrm{~g}$ of saturated fat, $12.7 \mathrm{~g}$ of total sugar and $151.4 \mathrm{mg}$ of $\mathrm{Na}$ with $9.5 \%$ of energy from saturated fat and $31.8 \%$ of energy from total sugar.

\section{Nutritional value (healthier or less healthy) and type of items purchased by students}

As seen in Table 4, less healthy items represented 72 and $76 \%$ of all items purchased at recess and lunch, respectively, with 'savoury snacks' and 'sugar-sweetened ice blocks and slushies' being the most common recess and lunch purchases, respectively.

\section{Association between school characteristics and nutrient composition and nutritional value of student purchases}

There were no differences in the nutrient composition or nutritional value of foods purchased by school characteristics including school location and school socio-economic region (Table 5).

\section{Discussion}

The present study sought to describe the nutritional quality of foods purchased by children from the school canteen and is the first of its kind to use objective observation data for student canteen purchases. Lunch was the most commonly used meal break, and lunch purchases on average contained a higher amount of energy, saturated fat, Na
Table 3 The nutrient composition of student canteen purchases at recess and lunch*, New South Wales, Australia, 2015

\begin{tabular}{|c|c|c|c|c|}
\hline \multirow[b]{3}{*}{ Variable } & \multicolumn{4}{|c|}{ Nutrient composition of purchases† } \\
\hline & \multicolumn{2}{|c|}{ Recess (N 644) } & \multicolumn{2}{|c|}{ Lunch $(N$ 1666) } \\
\hline & Median & IQR & Median & IQR \\
\hline Energy $(\mathrm{kJ})$ & $571 \cdot 2$ & $289 \cdot 2-1005 \cdot 0$ & 685.4 & $257 \cdot 5-1693 \cdot 6$ \\
\hline Saturated fat $(\mathrm{g})$ & 1.6 & $0.3-3 \cdot 3$ & $1 \cdot 8$ & $0.0-5.9$ \\
\hline Total sugar $(\mathrm{g})$ & $11 \cdot 6$ & $4 \cdot 3-17 \cdot 5$ & $12 \cdot 7$ & $6 \cdot 5-25 \cdot 1$ \\
\hline $\mathrm{Na}(\mathrm{mg})$ & $132 \cdot 4$ & $28 \cdot 1-313 \cdot 6$ & $151 \cdot 4$ & $16 \cdot 4-584 \cdot 2$ \\
\hline $\begin{array}{l}\% \text { Energy from } \\
\text { saturated fat }\end{array}$ & $10 \cdot 0$ & $2 \cdot 9-14 \cdot 1$ & $9 \cdot 5$ & $0 \cdot 0-14.5$ \\
\hline $\begin{array}{l}\% \text { Energy from } \\
\text { total sugar }\end{array}$ & $37 \cdot 8$ & $11 \cdot 2-65 \cdot 3$ & $31 \cdot 8$ & $16 \cdot 7-85 \cdot 8$ \\
\hline
\end{tabular}

IQR, interquartile range.

*Four items were found to have incorrect nutrition labels and their labels were replaced with a commercially equivalent product stocked at another school or using an online food database (Foodworks ${ }^{\circledR}$ version 7).

†The unit of analysis for nutrient composition was the 'purchase' which could consist of multiple items.

and total sugar than recess purchases. Across both meal breaks student purchases contained a high proportion of energy from total sugar $(31 \cdot 8-37 \cdot 8 \%)$ with the majority $(72-76 \%)$ of the items selected by students being less healthy choices. The most common type of item purchased at recess and lunch were 'savoury snacks' and 'sugarsweetened ice blocks and slushies', respectively. Overall the study found considerable opportunity to improve the nutritional quality of primary-school students' recess and lunch purchases.

The findings of the present study are consistent with previous self-reported studies regarding the nutritional value and types of foods purchased from school canteens ${ }^{(9,13,30)}$. For example, Carter and Swinburn (2004) found that 'less healthy choices' dominated sales by more than $2: 1$ in New Zealand primary-school canteens ${ }^{(31)}$. Similarly, Cleland et al. (2004) found that the most common foods purchased from the school canteen were less healthy choices including pies/pastries/sausage rolls ( $43.0 \%$ ), confectionery $(37.7 \%)$, potato crisps $(25 \cdot 2 \%)$ and chocolate $(20 \cdot 2 \%)^{(30)}$. The study conducted by Finch et al. (2006), in the same geographic region as the present study, similarly found lunch to be the most frequent meal break and that packets of crisps (37\%) and pies and sausage rolls (54\%) were the most frequently purchased recess and lunch items, respectively ${ }^{(13)}$. Such findings are broadly consistent with our findings despite the study being conducted 10 years later and the subsequent introduction of a state canteen policy. While state-wide policies have been introduced to improve the availability of foods consistent with dietary guidelines, the findings suggest that purchasing of unhealthy food via school canteens remains an important public health priority for the improvement of student nutrition. More comprehensive polices encompassing food availability, in addition to strategies targeting purchasing behaviour, may be required to improve student dietary intake. For example, a 
Table 4 The nutritional value and types of items purchased by students at recess and lunch*, New South Wales, Australia, 2015

\begin{tabular}{|c|c|c|c|c|c|c|c|}
\hline \multirow[b]{3}{*}{ Variable } & \multicolumn{7}{|c|}{ Nutritional value of items } \\
\hline & \multicolumn{3}{|c|}{ Recess (N 804) } & & \multicolumn{3}{|c|}{ Lunch (N 2475) } \\
\hline & $n$ & & $\%$ & & $n$ & & $\%$ \\
\hline Healthier $(\mathrm{H}) \dagger$ & 222 & & 28 & & 604 & & 24 \\
\hline \multirow[t]{2}{*}{ Less healthy (LH)† } & 582 & & 72 & & 1871 & & 76 \\
\hline & \multicolumn{3}{|c|}{ Common items purchased at recess } & & \multicolumn{3}{|c|}{ Common items purchased at lunch } \\
\hline Item & $n$ & $\%$ & Nutritional value & Item & $n$ & $\%$ & Nutritional value \\
\hline Savoury snack foods & 103 & 13 & LH & Ice blocks or slushies & 311 & 13 & LH \\
\hline Ice blocks or slushies & 98 & 12 & $\mathrm{LH}$ & Savoury pastries & 280 & 11 & LH \\
\hline Cakes, muffins, sweet pastries & 61 & 8 & $\mathrm{LH}$ & Crumbed chicken, fish, meat or vegetables & 200 & 8 & $\mathrm{LH}$ \\
\hline Low-fat milks & 60 & 7 & $\mathrm{H}$ & Ice creams \& dairy desserts & 196 & 8 & $\mathrm{LH}$ \\
\hline Confectionery & 54 & 7 & $\mathrm{LH}$ & Low-fat milks & 177 & 7 & $\mathrm{H}$ \\
\hline Ice cream \& dairy desserts & 53 & 7 & $\mathrm{LH}$ & Frozen fruit juice (<200 ml) & 170 & 7 & $\mathrm{H}$ \\
\hline Oven-baked potato products & 45 & 6 & $\mathrm{LH}$ & Sandwiches, wraps and burgers with crumbed meats or spread & 152 & 6 & $\mathrm{LH}$ \\
\hline Breads and alternatives $\S$ & 40 & 5 & $\mathrm{H}$ & Confectionery $\ddagger$ & 138 & 6 & $\mathrm{LH}$ \\
\hline Pizzas \| & 40 & 5 & $\mathrm{LH}$ & Savoury snack foods & 113 & 5 & $\mathrm{LH}$ \\
\hline Breads and alternatives§ & 39 & 5 & $\mathrm{LH}$ & Sugar-sweetened drinks & 111 & 4 & $\mathrm{LH}$ \\
\hline
\end{tabular}

${ }^{*}$ The unit of analysis for nutritional value was the individual item where each menu item represented a unique value.

†Foods were determined by a dietitian to be healthy if they were classified as 'green' and less healthy if they were classified as 'amber' or 'red' according to the New South Wales government school-canteen policy Fresh Tastes @ School (FT@S).

§Healthy 'breads and alternatives' are those with low levels of fat and sugar and can include pikelets and small servings of homemade herb or garlic bread. Less healthy 'breads and alternatives' are those with higher levels of fat and sugar and

|less healthy pizzas include those that are commercial or homemade with processed meats. 
recent trial which implemented a consumer behaviour intervention including strategies targeting improvements in healthy food availability, in addition to labelling, placement and prompting of healthy menu items, found the energy $(-567 \mathrm{~kJ} ; P<0.001)$, saturated fat $(-2.37 \mathrm{~g} ; P<0.001)$ and $\mathrm{Na}(-227 \mathrm{mg}, P<0.001)$ content of student lunch orders to be significantly lower in those allocated to the intervention compared with students in the control group ${ }^{(32)}$. This highlights the merit of implementing multiple consumer-targeted strategies to facilitate the purchase of healthier foods and may warrant the inclusion of such strategies, if not already, in state-wide canteen policies.

Interestingly, our research did not observe any differences in the mean energy, saturated fat, total sugar and $\mathrm{Na}$ content and nutritional value (healthier/less healthy) of student purchases within schools of high and low socio-economic area or by geographical location, despite evidence suggesting the food consumed by children from lower socio-economic backgrounds is of poorer nutritional quality ${ }^{(5,33)}$. Our findings are consistent with Finch et al. ${ }^{(13)}$ who found that student purchasing patterns, including the types of foods purchased from the canteen, are similar (less healthy) across both high and low socioeconomic groups. While the findings suggest that support to improve healthy purchases from school canteens is warranted for all children, strategies that are developed to ensure such support is beneficial for children from more disadvantaged backgrounds will ensure that existing disparities in the nutritional quality of students' overall diet $^{(5)}$ are not further exacerbated.

The study findings should be considered in the context of its methods. The strengths of the present study include its use of objective observational data for student purchases and rigorous procedures used to classify and assess menu items. Nevertheless, the study had a number of limitations. This was a cross-sectional sample conducted at one time point during one season (summer). Observations were, however, distributed across all days of the week with $27 \%$ occurring on Monday, $17 \%$ on Tuesday, $17 \%$ on Wednesday, $22 \%$ on Thursday and $17 \%$ on Friday. Even so, to better understand purchase patterns the study would be strengthened by taking multiple observations over the course of a week and during different seasons (winter and summer) as we would expect to see differences in the types of foods purchased in cooler months ${ }^{(34)}$. Additionally, while the sample size for student purchases were relatively large (lunch, $N$ 1666; recess, $N$ 644), an increased sample size would have a better ability to detect differences in the nutritional quality of student purchases within schools. Furthermore, schools with menus that were compliant with FT@S were excluded from the study sampling frame (as this was an eligibility criterion for inclusion in the larger RCT) and as such may have different purchasing patterns. While this represents a limitation, only $10 \%$ (eight schools) of the initial sample were compliant with the policy, with such compliance rates being consistent 
in almost all states in Australia except for Western Australia ${ }^{(35)}$. Therefore, these findings are likely to be representative of the population of interest. Finally, while the present study provides important information regarding student purchases, no data were collected regarding the consumption of foods and beverages purchased from the canteen. While we are not aware of any literature that reports the association between student canteen purchases and consumption, purchase data in other food-service settings have been shown to be highly correlated with food consumed $^{(36)}$.

Notwithstanding the limitations, the present study demonstrated that there is considerable scope to improve the nutritional quality of student purchases from primaryschool canteens. Future research is required to identify effective strategies to (i) enhance implementation and monitoring of school canteen policies and (ii) facilitate implementation of strategies that support the purchase of healthier foods from school canteens. The findings provide valuable information for policy makers and public health practitioners interested in supporting child nutrition.

\section{Acknowledgements}

Acknowledgements: The authors would like to thank the NSW Department of Education and Communities for permitting the study to be conducted in Hunter Region public schools. The authors would also like to acknowledge Katie Robertson, Emma Robson, Kage Gold, Belinda Marshall, Sarah Preece, Tamara Orr, Meagan Rose, Loren Fullager, Erin Corbett, Melinda Cooper and Irena Patsan for their assistance with data collection and Nicole Nathan for project management. Financial support: This study received funding through the Australian Research Council (ARC) Linkage Project Scheme (grant number LP130101008). Infrastructure support was provided by the University of Newcastle, Hunter New England Population Health (HNEPH) and the Hunter Medical Research Institute (HMRI). The ARC had no role in the design, analysis or writing of this article. R.W. and R.S. are supported by National Health and Medical Research Council (NHMRC) Translating Research into Practice Fellowships. L.W. is supported by a Heart Foundation Future Leader Fellowship (grant number 101175) and an NHMRC Career Development Fellowship (grant number APP1128348). S.L.Y. is supported by the National Heart Foundation (postdoctoral research fellowship). Conflict of interest: All authors declare they have no conflicts of interest. Authorship: T.D., L.W., S.Y., R.W., R.S. and J.W. contributed to the study method. L.J., K.R. and T.D. contributed to data collection and intervention development. T.D., R.S., R.W., L.W., C.L., L.J., K.R., J.W. and S.L.Y. contributed to manuscript development. All authors reviewed, edited and approved the final manuscript. Ethics of buman subject participation: This study was conducted according to the guidelines laid down in the Declaration of Helsinki and all procedures involving human subjects were approved by the Human Research Ethics Committee of the University of Newcastle (approval number H-2008-0343), the Hunter New England Human Research Ethics Committee (approval number 06/07/26/4.04) and the NSW Department of Education and Communities (approval number SERAP 2012277). Written informed consent was obtained from participating schools.

\section{References}

1. World Health Organization (2004) Global Strategy on Diet, Physical Activity and Health. http://www.who. int/dietphysicalactivity/goals/en/index.html (accessed 8 December 2013).

2. Bates B, Lennox A \& Prentice A (2014) National Diet and Nutrition Survey: Results from Years 1-4 (Combined) of the Rolling Programme (2008/2009-2011/12): Executive Summary. London: Public Health England.

3. National Cancer Institute (2015) Epidemiology and Genomics Research Program. Usual Dietary Intakes: Food Intakes US Population, 2007-10. https://epi.grants.cancer. gov/diet/usualintakes/pop/2007-10/ (accessed May 2015).

4. Australian Bureau of Statistics (2014) ABS 4364.0.55.007 Australian Health Survey: Nutrition First Results - Foods and Nutrients, 2011-12. http://www.abs.gov.au/ausstats/abs@. nsf/Lookup/4364.0.55.007main+features12011-12 (accessed October 2017).

5. Kelly C, Callaghan M, Molcho M et al. (2018) Food environments in and around post-primary schools in Ireland: associations with youth dietary habits. Appetite 132, 182-189.

6. Maynard M, Gunnell D, Emmett P et al. (2003) Fruit, vegetables, and antioxidants in childhood and risk of adult cancer: the Boyd Orr cohort. J Epidemiol Community Health 57, 218-225.

7. World Health Organization (2012) Population-Based Approaches to Childhood Obesity Prevention. Geneva: WHO.

8. Bell AC \& Swinburn B (2004) What are the key food groups to target for preventing obesity and improving nutrition in schools? Eur J Clin Nutr 58, 258-263.

9. Utter J, Schaaf D, Mhurchu C et al. (2007) Food choices among students using the school food service in New Zealand. $N Z$ Med J 120, 1248.

10. Winson A (2008) School food environments and the obesity issue: content, structural determinants, and agency in Canadian high schools. Agric Hum Values 25, 499-511.

11. Hardy L, Mihrshahi S, Drayton B et al. (2017) NSW Schools Physical Activity and Nutrition Survey (SPANS). Report no. 1760006386. North Sydney, NSW: NSW Department of Health.

12. Lawlis T, Knox M \& Jamieson M (2016) School canteens: a systematic review of the policy, perceptions and use from an Australian perspective. Nutr Diet 73, 389-398.

13. Finch M, Sutherland R \& Harrison M et al. (2006) Canteen purchasing practices of year 1-6 primary school children and association with SES and weight status. Aust $N Z J$ Public Health 30, 247-251.

14. NSW Department of Health \& NSW Department of Education and Training (2006) Fresh Tastes @ School, NSW Healthy School Canteen Strategy: Canteen Menu Planning Guide. Sydney, NSW: NSW Department of Health and NSW Department of Education and Training. 
15. New South Wales Department of Education (2014) Nutrition in Schools Policy. https://education.nsw.gov.au/policylibrary/policies/nutrition-in-schools-policy (accessed July 2019).

16. Pink B (2011) Australian Statistical Geography Standard (ASGS) Volume 1 - New South Wales Map. In Australian Bureau of Statistics. Main Structure and Greater Capital City Statistical Areas. Canberra, ACT: Australian Bureau of Statistics.

17. Australian Bureau of Statistics (2016) 2016 Census QuickStats: Hunter. http://quickstats.censusdata.abs.gov.au/census_ services/getproduct/census/2016/quickstat/CED121 (accessed February 2019).

18. New South Wales Department of Education (2016) Master dataset: NSW government school locations and student enrolment numbers. https://data.cese.nsw.gov.au/data/dataset/nswpublic-schools-master-dataset (accessed February 2019).

19. Wolfenden L, Nathan N, Janssen LM et al. (2017) Multistrategic intervention to enhance implementation of healthy canteen policy: a randomised controlled trial. Implement Sci $12,6$.

20. Clinton-McHarg T, Janssen L, Delaney T et al. (2018) Availability of food and beverage items on school canteen menus and association with items purchased by children of primary-school age. Public Health Nutr 21, 2907-2914

21. Kraisid T, MacLean W \& Warwick P (2002) Food Energy: Methods of Analysis and Conversion Factors: Report of a Technical Workshop, Rome, 3-6 December. Rome: FAO.

22. Williams CM, Nathan N, Delaney T et al. (2015) CAFE: a multicomponent audit and feedback intervention to improve implementation of healthy food policy in primary school canteens: protocol of a randomised controlled trial. BMJ Open $\mathbf{5}$, e006969.

23. Billich N, Adderley M, Ford L et al. (2018) The relative price of healthy and less healthy foods available in Australian school canteens. Health Promot Int. Published online: 12 April 2018. doi: 10.1093/heapro/day025.

24. National Health and Medical Research Council (2013) Australian Dietary Guidelines. Canberra, ACT: NHMRC.
25. US Department of Health and Human Services \& US Department of Agriculture (2015) 2015-2020 Dietary Guidelines for Americans, 8th ed. Washington, DC: USDA and DHHS.

26. Health Canada (2019) Canada's Dietary Guidelines. Ottawa, ON: Health Canada.

27. Australian Curriculum Assessment and Reporting Authority. (2016) My School. https://www.myschool.edu.au/ (accessed 26 March 2016).

28. NSW Department of Education, Centre for Education Statistics and Evaluation (2016) Schools and Students: 2016 Statistical Bulletin. https://www.cese.nsw.gov.au//images/ stories/PDF/2016_statistical_bulletin_AA.pdf (accessed July 2019).

29. Australian Bureau of Statistics (2011) Technical Paper: SocioEconomic Indexes for Areas. Canberra, ACT: Australian Bureau of Statistics.

30. Cleland V, Worsley A \& Crawford D (2004) What are grade 5 and 6 children buying from school canteens and what do parents and teachers think about it? Nutr Diet 61, 145-150.

31. Carter MA \& Swinburn B. (2004) Measuring the 'obesogenic' food environment in New Zealand primary schools. Health Promot Int 19, 15-20.

32. Delaney T, Wyse R, Yoong SL et al. (2017) Cluster randomized controlled trial of a consumer behavior intervention to improve healthy food purchases from online canteens. $\mathrm{Am}$ J Clin Nutr 106, 1311-1320.

33. Sanigorski A, Bell A, Kremer P et al. (2005) Lunchbox contents of Australian school children: room for improvement. Eur J Clin Nutr 59, 1310-1316.

34. Capita R \& Alonso-Calleja C (2005) Differences in reported winter and summer dietary intakes in young adults in Spain. Int J Food Sci Nutr 56, 431-443.

35. Woods J, Bressan A \& Langelaan C (2014) Australian school canteens: menu guideline adherence or avoidance? Health Promot J Austr 25, 110-115.

36. Ransley JK, Donnelly JK, Khara TN et al. (2001) The use of supermarket till receipts to determine the fat and energy intake in a UK population. Public Health Nutr 4, 1279-1286. 